\title{
A Cooperative Dynamic Approach to Pairs Trading
}

\author{
J. P. Ramos-Requena $\mathbb{D}^{1}{ }^{1}$ M. N. López-García $\mathbb{D},{ }^{1}$ M. A. Sánchez-Granero $\mathbb{D},^{2}$ \\ and J. E. Trinidad-Segovia (D) \\ ${ }^{1}$ Departamento de Economía y Empresa, Universidad de Almería, La Cañada de San Urbano, Almería 04120, Spain \\ ${ }^{2}$ Departamento de Matemáticas, Universidad de Almería, La Cañada de San Urbano, Almería 04120, Spain
}

Correspondence should be addressed to J. P. Ramos-Requena; jpramosre@ual.es

Received 24 August 2021; Accepted 30 September 2021; Published 13 October 2021

Academic Editor: Paulo Jorge Silveira Ferreira

Copyright (c) 2021 J. P. Ramos-Requena et al. This is an open access article distributed under the Creative Commons Attribution License, which permits unrestricted use, distribution, and reproduction in any medium, provided the original work is properly cited.

\begin{abstract}
Based on recent works on stocks comovement, Pairs Trading's strategy is enhanced by reducing the stock universe to the stocks with the lower volatility on a given date. From this universe of low volatility stocks, pairs are selected by looking for pairs whose series present a high degree of antipersistence. Finally, a "reversion to the mean" strategy is applied to these pairs. It is shown that, with this approach to Pairs Trading, positive results can be obtained for stock from the Nasdaq stock exchange, mainly during bull markets and low volatility periods.
\end{abstract}

\section{Introduction}

Statistical arbitrage techniques became a popular research topic after the pioneer paper of Gatev et al. [1] who proved that this methodology was able to obtain positive results in US market during a period of 30 years (1962-1997). Pairs trading strategies are structured as follows: during the formation period, two securities are identified, whose prices have moved together historically. These securities are considered in equilibrium, which is identified by a proposed model. In the second step, the trading period, the spread of their joined movement is monitored. As it is assumed that there is an equilibrium relationship between the pair, the expectation is that the spread will revert to the historical mean. Consequently, if the prices diverge, and the spread widens between the pair, the trading strategy will consist in selling short the better performing stock and purchasing the worst performing one.

Researchers have proposed different methodologies and techniques. The pioneer paper of Gatev et al. [1] introduced the most popular methodology, the distance method, lately used by Do and Faff $([2,3])$. Chen et al. [4] also used this methodology but introduced the Pearson correlation on return level for identifying pairs and constructing an empirical metric to quantify return divergence of the pair.
Vidyamurthy [5] introduced the cointegration approach. This approach has a higher potential of identifying true longterm equilibrium relationships between assets. Lin et al. [6] introduced a minimum profit condition for a pair of securities that is cointegrated over a time horizon. Later, Puspaningrum et al. [7] fitted an AR(1)-process to the spread of two cointegrated stocks. The authors proposed an integral equation approach to numerically evaluate the estimated number of trades for any given trading threshold or minimum profit per trade to optimize the total profit. Law et al. [8] presented an alternative implementation of the cointegration approach by introducing a statistic, which combines return maximization and risk minimization simultaneously. Clegg et al. [9] use partial cointegration as a means of identifying pairs to develop the Pairs Trading strategy, using the components of the S\&P 500 over the period 1990 to 2015, where they obtain annualized returns in excess of $12 \%$ after transaction costs.

Dunis and Ho [10] introduced the Multivariate Cointegration Approach. The authors used cointegration relationships to construct index tracking portfolios by considering different subsets of the index components and estimate the joint cointegration vector for these subsets and the index. Galenko et al. [11] used a multivariate cointegration framework by performing extensive data mining. 
The authors used different frequencies and also took different duration of the formation period to estimate the cointegration vector. Finally, the recent work of Yiyun and Law [12] proposed dynamic parameterization (ADFthreshold, adjusted ASR-threshold, and conditional cointegration coefficients) to accommodate different market conditions.

Elliot et al. [13] introduced the time series approach by describing the spread with a mean-reverting Gaussian Markov chain. Do et al. [14] employed theoretical pricing methods at the return instead of the price level, and Jure and Yang [15], the stochastic control approach. Bertram [16] and Cummins et al. [17] assumed that the spread follows a zeromean symmetric Ornstein-Uhlenbeck Process. Bock and Mestel [18] used a Markov switching model to develop a pairs trading model, Chen et al. [19] constructed a pairs trading strategy with three-regime threshold autoregressive models with GARCH effects, and Göncü and Akyildirim [20] introduced an Ornstein-Uhlenbeck process for the dispersion of the different assets.

Jurek and Yang [15] did the pioneer paper where the Stochastic Control Approach is used. In this paper, the authors derived the Hamilton-Jacobi-Bellmann (HJB) equation to find closed-form solutions for the value and policy functions. Following this line, Liu and Timmermann [21] derived optimal portfolio holdings for convergence trades under diverse arbitrage opportunities. The portfolio incorporates the arbitrage opportunity and the diversification benefits. Huck $[22,23]$ proposed a three-stage methodology: forecasting, outranking, and trading by building and combining an artificial neural networks and a multicriteria decision method.

Considering the returns negative skewness and excess kurtosis, recent contributions are based in Copula Approach. Ferreira [24], Liew and Wu [25], Stander et al. [26], Xie and $\mathrm{Wu}$ [27], Krauss and Stubinger [28], or Rad et al. [29] are the most representative papers of the copula methods based on parametric and nonparametric approaches. However, only Krauss and Stubinger [28] used a Copula Method for pairs selection and trading. The rest of papers used the Distance or the Cointegration approach for pairs selection.

This research is based on two previous lines. The first one is the new approach introduced by Ramos-Requena et al. $[30,31]$ as an alternative methodology to correlation and cointegration, which is based on Hurst Exponent. The second one is based on the works of López-García et al. $[32,33]$ where a new measure of the assets comovement based on physical particles dynamics is introduced. The novelty of this contribution to pairs trading literature is the introduction of a preselection procedure of the stocks universe, where the pairs are selected. This preselection is based on the degree of comovement among the stocks of a specific market or index.

\section{A New Methodology for Pairs Selection}

The selection of the stocks to form a pair in a Pairs Trading strategy is one of the more crucial steps of this strategy. The main goal is to select some pairs, such that the two stocks of the pair have a high level of comovement. It is usual to measure the degree of comovement (using different tools) of two stocks and select the pairs with a higher level of comovement and we will do this, but in order to improve the selection process, we will prefilter the stock universe first.

In López-García et al. ( [33]), log-price and volatility comovement is studied for stocks from the Nasdaq stock exchange. They found that stocks with low volatility tend to have a higher degree of both kinds of comovement. In fact, during noncrisis periods, the degree of comovement among stocks with low volatility is significantly higher that among random stocks.

Based on these results, we propose the following selection method: in the first stage, we select the 50 stocks from our universe (stocks from the Nasdaq stock exchange) with the lower volatility at the selection date; in the second stage, we look for pairs from stocks of this 50 low volatility stocks with a high degree of comovement, based on the Hurst exponent of the pair (we look for pairs with low Hurst exponent).

In López-García et al. [33], they used three comovement functions in order to measure the degree of comovement of all (or a subset of) stocks forming a given market. These functions were based on comovement studies on physical particle systems.

Traditionally, the study of financial markets has been related to Brownian motion, considering the market as if it were a system of many bodies. The prices of the assets that make up the market in the short term can show identifiable patterns, but thanks to speculators who try to take advantage of this pattern, this pattern ends up being eliminated in the long term, adjusting prices to their center of mass, that is to say, to their index.

Based on the Brownian motion of colloidal systems, López-García et al. ( [33]) proposed three functions to control the cooperative dynamics of financial systems. In this paper, we have used their third function:

$$
\begin{aligned}
C_{3 t}(\tau) & =\frac{\sum_{i, j} \delta x_{i}(t, \tau) \delta x_{j}(t, \tau)}{\sum_{i, j}\left|\delta x_{i}(t, \tau) \delta x_{j}(t, \tau)\right|}, \\
C_{3}(\tau) & =<C_{3 t}(\tau)>.
\end{aligned}
$$

Depending on what kind of comovement is being studied (log-price or volatility comovement), $x_{i}$ denotes the log-price or the volatility of stock $i$, and $\delta x_{i}(t, \tau)=x_{i}(t+$ $\tau)-x_{i}(t)$ for each date $t$ and each increment $\tau$.

The $C_{3 t}(\tau)$ function is a measure of the comovement (in $\log$-price or in volatility) for stocks $i$ and $j$ from time origin $t$, averaging the product of the changes for all pairs of stocks. On the other hand $C_{3}(\tau)$ is the mean of the previous measure over all time origins $t$, so it provides the mean comovement in a given period. Stock volatility has been calculated as the standard deviation of one-year log returns.

The possible results of this functions range from -1 to 1 . When values close to 0 are obtained, it means that there is no comovement. If the result is a positive number up to 1 , the stocks will be moving in the same direction, so we will have a 
positive comovement. On the contrary, when we obtain negative results up to -1 , the shares move in opposite directions, with the comovement being negative.

In Figures 1, 2 and 3 the comovement in different periods is shown. It is shown that the comovement in the period 2008-2013 (Figure 1) and in the period 2014-2019 (Figure 2) of the 50 stocks with lower volatility is quite high (above 0.4 in the full period). It is even higher (above 0.6) for the 2019-2020 period (Figure 3).

The study has been carried out using the period from 2008 to 2021, spread over the periods 2008-2013, 2013-2019, and 2018-2021.

It is clear that the comovement of the 50 stocks with the lower volatility is quite high and well above the general market comovement, so this selection of stocks seems a good candidate to apply pairs selection methods.

\section{Hurst Exponent}

To carry out our study, we are going to apply the Hurst exponent. This exponent was introduced by the hydrologist H. E. Hurst in 1951 [34] with the main objective of studying the problem of reservoir control for the Nile river dam. Since then, it has been applied in different disciplines to study memory [35].

Since its appearance, different estimation methodologies have been applied, among the most important of which are the R/S analysis [36] and the DFA [37]. But in different studies [38-41] among others, some accuracy problems were found. Then, new algorithms have been developed with the aim of estimating this indicator more efficiently.

Within the financial sphere, the GHE algorithm stands out, which was defined by Barabasi in 1991 [42]. This algorithm (GHE) is based on the scaling behavior of the statistic

$$
K_{q}(\tau)=\frac{\left\langle|X(t+\tau)-X(t)|^{q}\right\rangle}{\left\langle|X(t)|^{q}\right\rangle}
$$

which is given by

$$
K_{q}(\tau) \propto \tau^{q H},
$$

where $\tau$ is the scale (usually chosen between 1 and a quarter of the length of the series), $H$ is the Hurst exponent, $\langle\cdot\rangle$ denotes the sample average on time $t$ and $q$ is the order of the moment considered. In this paper, we will always use $q=1$.

The GHE is calculated by linear regression, taking logarithms in the expression contained in (3) for different values of $\tau[43,44]$.

In relation to the value of $H$, we can find that

(i) If $H$ is greater than 0.5 , the process is persistent

(ii) If $H$ is less than 0.5 , it is antipersistent

(iii) A Brownian motion has $H=0.5$

In this paper, we are interested in pairs with antipersistent characteristics, so we will look for pairs whose series has the lowest Hurst exponent.

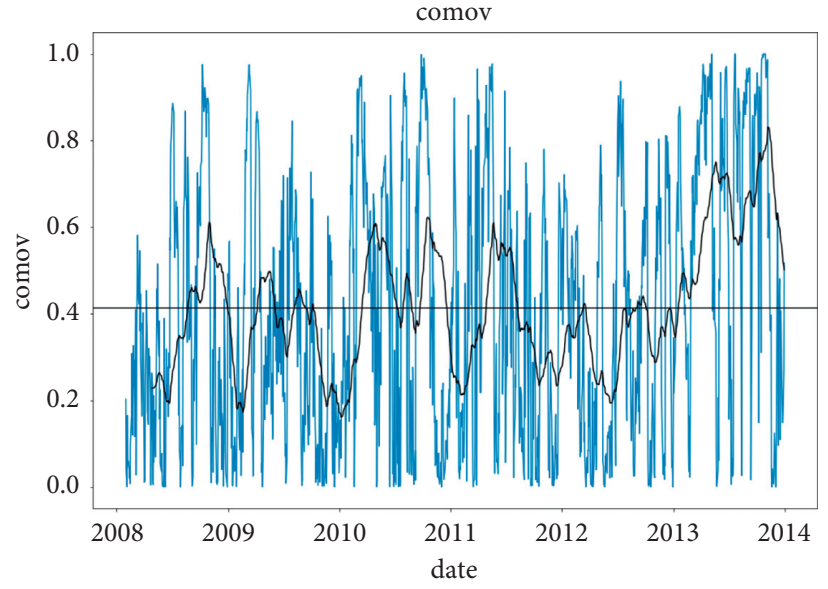

FIGURE 1: Monthly comovement $\left(C_{3 t}(20)\right)$ of the 50 stocks with the lower volatility each date from 2008 to 2014 . Blue line is the daily comovement, while black line is a moving average of the blue line with a time window of 60 trading days.

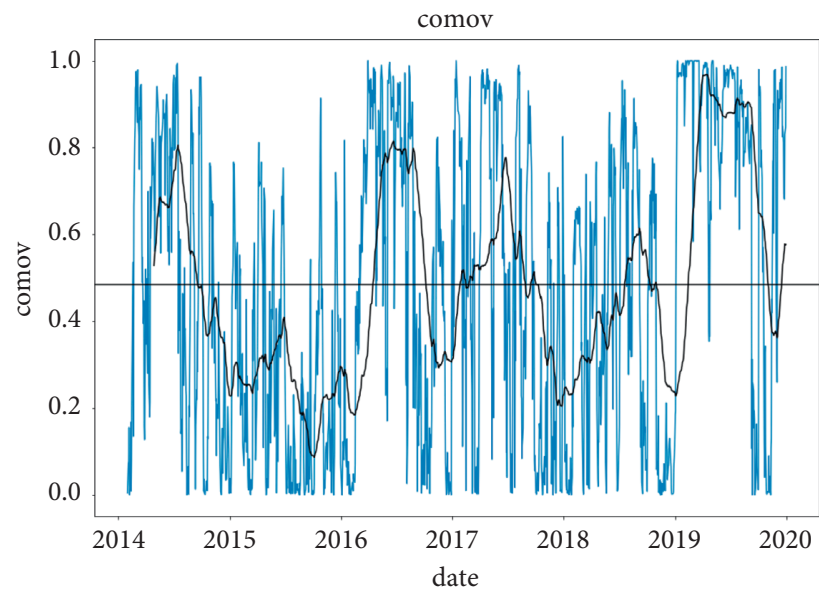

Figure 2: Monthly comovement $\left(C_{3 t}(20)\right)$ of the 50 stocks with the lower volatility each date from 2014 to 2020 . Blue line is the daily comovement, while black line is a moving average of the blue line with a time window of 60 trading days.

\section{Pairs Trading Strategy}

Once the 50 stocks with the lowest volatility have been selected, we select the pairs from that 50 -stock universe. In order to do that, we follow the method defined by RamosRequena et al. [31] (see also [45]). Given a pair candidate of stocks $A$ and $B$, we define the pair series as $s(b)(t)=p_{A}(t)$ $-b p_{B}(t)$, where $p_{A}(t)$ is the logarithm of the price of stock $A$ at time $t, p_{B}(t)$ is the logarithm of the price of stock $B$ at time $t$ and $b$ is the quantity invested in stock $B$ for each dollar invested in stock $A$. We try to find a value of the weight factor $b$ so that the series of the pair $s(b)$ has the smallest Hurst exponent, so we try to make the series as antipersistent as possible. What we are looking for is a value of $b$ that minimizes the function $f(b)=H(s(b))$, where $H(s(b))$ is the Hurst exponent of the pair series $s(b)$. Then, we take the pairs with the lowest Hurst exponent of their pair series. 


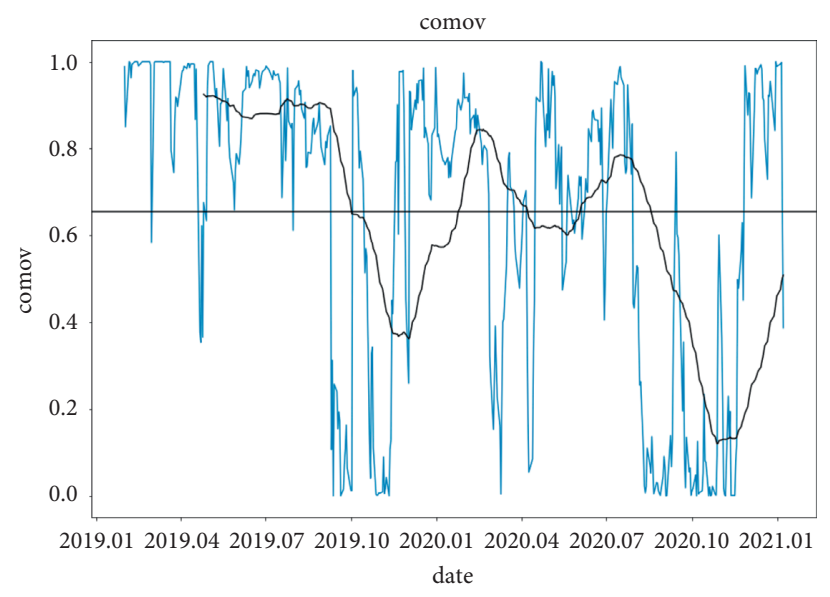

Figure 3: Monthly comovement $\left(C_{3 t}(20)\right)$ of the 50 stocks with the lower volatility each date from 2019 to 2021 . Blue line is the daily comovement, while black line is a moving average of the blue line with a time window of 60 trading days.

Once we have selected the pairs with lower Hurst exponent from the universe of the 50 stocks with the lowest volatility, we finish the selection phase. The pairs trading strategy is applied through two phases. In the first phase, the selection phase, the last 250 trading days (around one year) is used to select 10,20 , or 30 pairs following the previous procedure. In the second phase, the trading phase, each selected pair is traded for the next 120 days (around six months) using the next "reversion to the mean" strategy:

Let $s$ be the pair series, $m$ the average of the series $s$, and $\sigma$ the standard deviation of $m-s$ [46], then

(i) If $m+2 \sigma>s>m+\sigma$, the pair will be sold at $s_{0}$. The position will be closed when $s<m$ or $s>s_{0}+\sigma$.

(ii) If $m-2 \sigma<s<m-\sigma$, the pair will be bought at $s_{0}$. The position will be closed when $s>m$ or $s<s_{0}-\sigma$.

Note that the pair is bought when stock $A$ is bought and stock $B$ is sold ( $b$ dollars are sold of stock $B$ for each dollar bought of stock $A$ ). The pair is sold when stock $A$ is sold, while stock $B$ is bought ( $b$ dollars are bought of stock $B$ for each dollar sold of stock $A$ ).

\section{Empirical Results}

For the empirical application, we have taken the stocks from the US Nasdaq stock exchange, for the periods 2000-2002, 2003-2007, 2007-2009, 2008-2013, 2014-2019, and 2018-2021 (the data cover from 2000 to $01-01$ to 2021-03-19), taking these periods coinciding with different crises (of 2 years) and bull markets (of 4-5 years).

Note that previous studies, such as Ramos-Requena et al. [30], show that, in periods of high volatility, the Pairs Trading strategy is an optimal strategy.

Having selected the assets with the lowest volatility as explained in section 2 and applied the Pairs Trading strategy defined in section 4 , we will now present the main results obtained.

Table 1 shows the main results obtained from this study. It shows the number of pairs in the portfolio, the number of trades to be made in the period, the average annualized return, the Sharpe ratio, and the return for the period after deducting transaction costs.

In this paper, a transaction cost of $0.01 \%$ has been taken into account, which is what an investor would have to pay in a stock market operation of these characteristics.

In this case, as shown in Table 1, we can observe that the strategy performs very well for a portfolio composed of 10 pairs in the period 2014 to 2019 with a Sharpe ratio of 2.38; the same is true for the portfolio composed of 20 pairs during the period 2008 to 2013.

As can be seen in Table 1, for most of the periods studied, the Sharpe ratio is over 1 or even above that value. It is significant that the Sharpe ratio values are close to 0 or negative in periods with large market declines, as is the case for the period 2000 to 2002, the period 2007 to 2009, and the period 2018 to 2021; as can be seen, except for the 10 pairs portfolio in the period 2007-2009 and the period 2018 to 2021, all other values are negative.

If we look at average annual returns, we can see that the best results are obtained for the period 2008 to 2013 for the portfolio composed of 10 pairs with an annual return of 5.9\% and the portfolio composed of 20 pairs with a return of $5.40 \%$. As we can see for the periods 2000 to 2002 and 2007 to 2009 , the returns are negative, periods in which the financial markets suffered large losses.

With regard to profits after transaction costs (transaction costs have been considered $0.01 \%$ ), results show that it is for the period 2008 to 2013 when the profitability of the investment is higher $(27.49 \%, 25.32 \%$, and $21.99 \%)$. The same occurs for the periods 2003 to 2007 and 2014 to 2019 with positive returns. However, as with the other indicators studied, it is not profitable to invest in the periods 2000 to 2002 and 2007 to 2009.

Results also show that the preselection technique used can significantly improve the strategy. We will like to remark that to select portfolios with lower volatility is not a good option for applying the Pairs Trading strategy during periods of large stock market falls. In these periods, when a general Pairs Trading strategy is profitable (see, for example RamosRequena et al. [30]), a simple explanation is that, during 
TABle 1: Results.

\begin{tabular}{|c|c|c|c|c|c|}
\hline Period & Pairs & Operations & Average annual return & Sharpe ratio & Profits \\
\hline $2000-2002$ & 10 & 245 & $-3,70 \%$ & -0.81 & $-6,35 \%$ \\
\hline $2000-2002$ & 20 & 434 & $-4,20 \%$ & -1.11 & $-7,22 \%$ \\
\hline $2000-2002$ & 30 & 630 & $-3,40 \%$ & -0.95 & $-5,91 \%$ \\
\hline $2003-2007$ & 10 & 742 & $3,80 \%$ & 1.04 & $12,86 \%$ \\
\hline $2003-2007$ & 20 & 1266 & $3,10 \%$ & 1.11 & $10,57 \%$ \\
\hline $2003-2007$ & 30 & 1689 & $3,20 \%$ & 1.36 & $11,04 \%$ \\
\hline $2007-2009$ & 10 & 264 & $2,60 \%$ & 0.41 & $4,14 \%$ \\
\hline $2007-2009$ & 20 & 458 & $-0,50 \%$ & -0.09 & $-1,03 \%$ \\
\hline $2007-2009$ & 30 & 588 & $-2,30 \%$ & -0.50 & $-4,00 \%$ \\
\hline $2008-2013$ & 10 & 807 & $5,90 \%$ & 1.63 & $27,49 \%$ \\
\hline $2008-2013$ & 20 & 1351 & $5,40 \%$ & 1.91 & $25,32 \%$ \\
\hline $2008-2013$ & 30 & 1808 & $4,70 \%$ & 1.68 & $22,00 \%$ \\
\hline $2014-2019$ & 10 & 969 & $4,90 \%$ & 2.38 & $22,73 \%$ \\
\hline 2014-2019 & 20 & 1685 & $2,00 \%$ & 0.60 & $8,86 \%$ \\
\hline 2014-2019 & 30 & 2272 & $2,60 \%$ & 0.89 & $11,64 \%$ \\
\hline $2018-2021$ & 10 & 287 & $-2,50 \%$ & -0.34 & $-2,79 \%$ \\
\hline $2018-2021$ & 20 & 576 & $1,00 \%$ & 0.18 & $0,71 \%$ \\
\hline $2018-2021$ & 30 & 787 & $1,90 \%$ & 0.43 & $1,64 \%$ \\
\hline
\end{tabular}

prolonged bear markets, the volatilities of all stocks go up, so our selection of the 50 stocks with the lower volatility may change faster than in normal periods. Note that we update the 50 stocks with the lower volatility each 120 trading days (about half a year), and this could be too late, since the volatilities may have changed too much.

Below, we show different graphs for the periods studied, showing the evolution of the cumulative logarithmic return.

Figure 4 shows the cumulative logarithmic return for a portfolio composed of 30 pairs for the study period 2003 to 2007. As can be seen, the graph starts in 2004, because, as explained in section 4 , the selection period is 250 days, and the strategy starts from 251 days for 180 days, which is why it appears from 2004 onwards.

With respect to the cumulative logarithmic return, it can be observed that, during the 2005 financial year, there is a great growth, reaching a profitability of close to $10 \%$ in July during 2006 until the end of the study period, and it remains between $8 \%$ and $10 \%$, to reach the maximum profitability at the end of 2007 with a profitability of more than $11 \%$. As can be seen during this period, it is a good option to opt to follow a Pairs Trading strategy, obtaining a good profitability, as shown in Table 1.

Figure 5 shows the cumulative logarithmic return for a portfolio composed of 30 pairs for the period 2007 to 2009. In this case, it can be seen that the return during the period is negative; it is significant that, in August 2008, the highest cumulative return of around $4 \%$ is obtained, but from that date onwards, it begins to decrease, reaching below $-6 \%$ in July 2009. It can be seen that despite being a period of high volatility, in this case, the expectations of this strategy in this period are not met, and it would not be a recommendable strategy to employ.

If there was a recommended period for applying this strategy, it is for the period 2008 to 2013, as shown in Figure 6. This figure shows the cumulative logarithmic return for a portfolio composed of 20 pairs. It can be seen that, until 2010, the return is negative, but it is from the

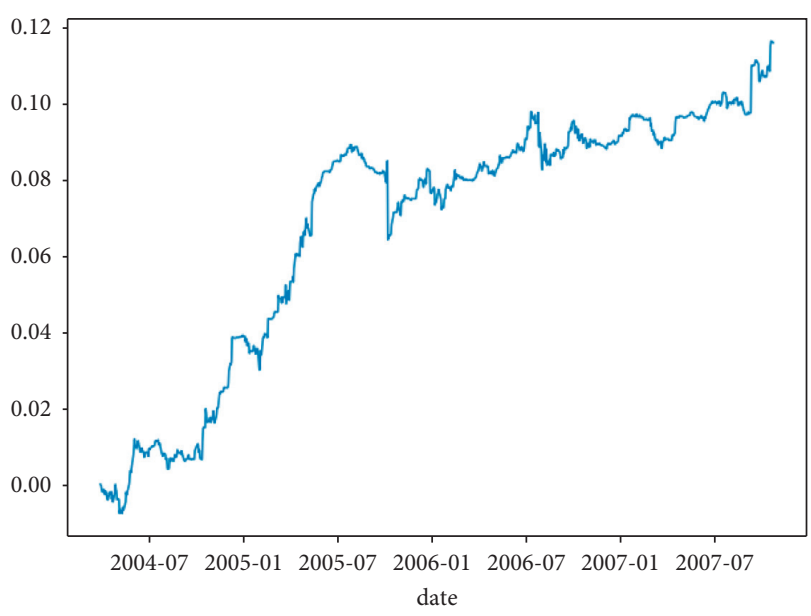

FIGURE 4: Cumulative logarithmic returns for a 30-pair portfolio in the period 2003 to 2007.

beginning of 2010 until the end of 2013 that the cumulative return begins to grow, reaching a level of over $25 \%$ from 2013 onwards. Despite the high volatility dates since 2008, it is not a strategy that works as it is being developed in this paper, since despite being a market-neutral strategy, in this case, it can be observed that it is affected by movements in the financial markets.

Figure 7 shows the cumulative logarithmic return for the period 2014 to 2019 for a portfolio composed of 10 pairs. It can be seen that, in this period, it is growing steadily, reaching over $20 \%$ from 2019 onwards. As in the previous period, it can be seen that this is a good investment strategy.

Finally, Figure 8 shows the cumulative logarithmic return for the period 2019 to 2021; in this case, we can see an upward and downward movement during the period from March to July 2020, coinciding with the falls suffered by the stock markets caused by the restrictions taken to fight the COVID-19 pandemic. It can be seen that the highest return of more than $7 \%$ is achieved during the month of June. 


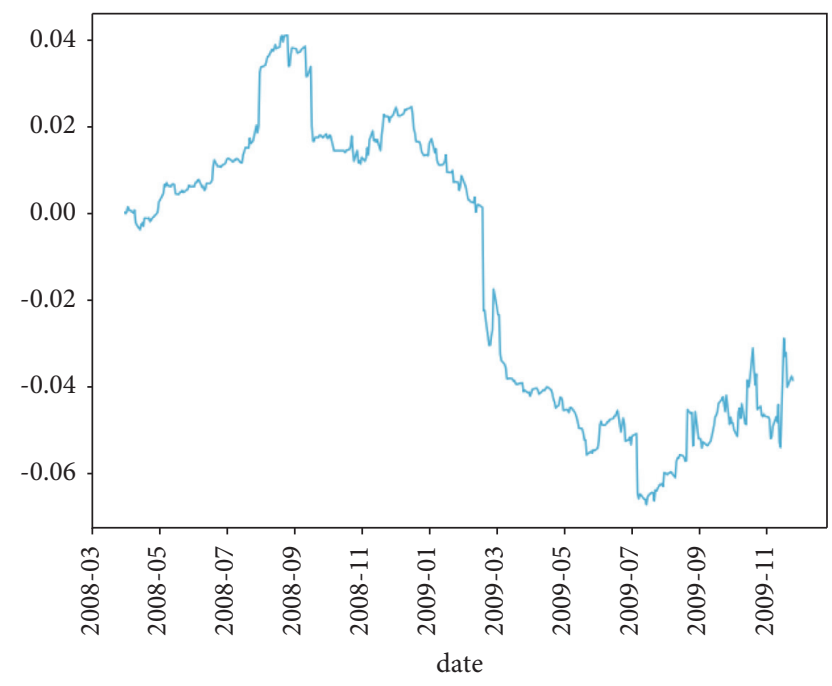

FIGURE 5: Cumulative logarithmic returns for a 30-pair portfolio in the period 2007 to 2009 .

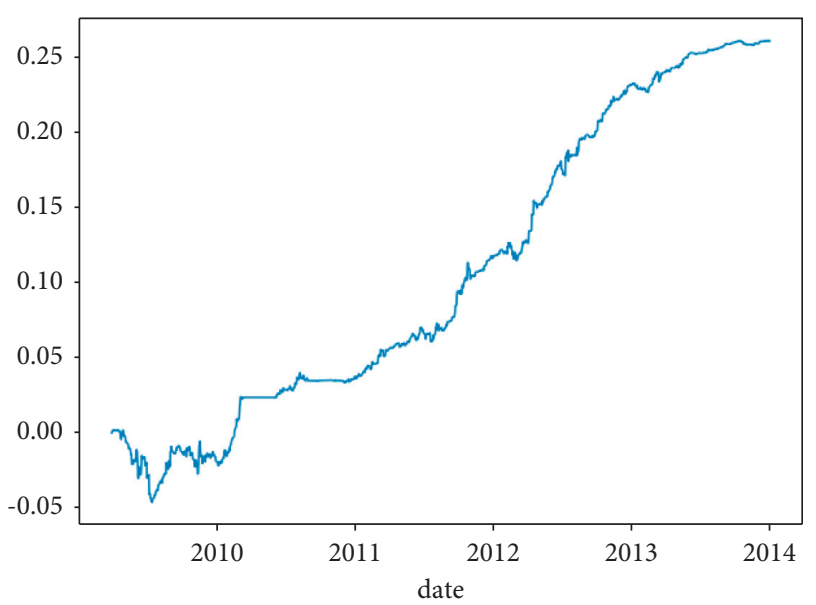

FIGURE 6: Cumulative logarithmic returns for a 20-pair portfolio in the period 2008 to 2013.

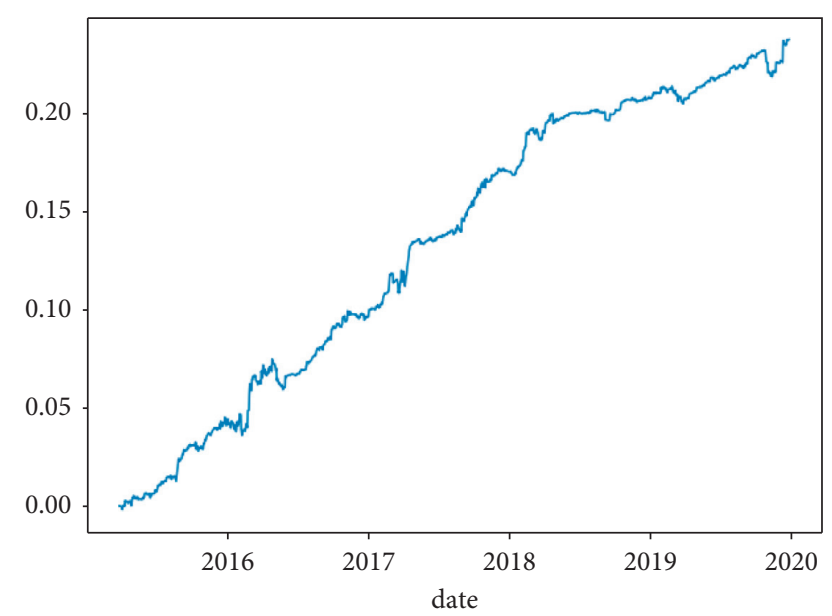

FIGURE 7: Cumulative logarithmic returns for a 10-pair portfolio in the period 2014 to 2019 .

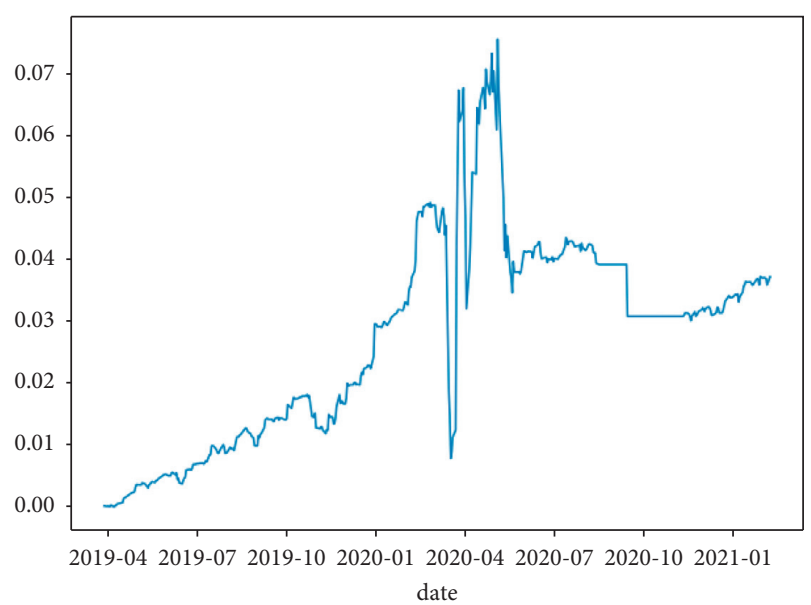

FIGURE 8: Cumulative logarithmic returns for a 30-pair portfolio in the period 2018 to 2021.

As it can be seen, including this new methodology for pair selection allows us to employ the Pairs Trading strategy in periods where it was not very profitable before, thus making this strategy more attractive to investors.

\section{Conclusions}

Pairs Trading is a market-neutral statistical arbitrage strategy. Recent studies (Ramos-Requena et al. [30]) have proved that it is a profitable strategy in periods of high instability in developed markets and also in nonefficient markets (Sanchez-Granero et al. [47] and Balladares et al. [48]) such as emerging ones.

One of the critical steps in Paris Trading is the pairs selection, but not too much attention has been given to the stock universe before pairs selection. In this paper, we have introduced a preselection procedure based on the stocks comovement measure through comovement functions based on comovement studies on physical particle systems. Therefore, portfolios with less volatile stocks have been selected, and it has been observed that, with this new modification, Paris Trading is also profitable in periods of low volatility.

However, on high volatility conditions, the strategy does not work as good. A plausible explanation of this phenomenon could be that, during periods with prolonged downward movements in the markets, volatility of the stocks is increased, and the model proposed in this paper is too slow to capture this faster change in the volatility of the preselected stocks.

\section{Data Availability}

There are no published data from this study.

\section{Conflicts of Interest}

The authors declare that they have no conflicts of interest. 


\section{Acknowledgments}

M.A. Sánchez-Granero acknowledges the support of grants PGC2018-101555-B-I00 (Ministerio Español de Ciencia, Innovación y Universidades and FEDER) and UAL18-FQMB038-A (UAL/CECEU/FEDER) and CDTIME. J.E. Trinidad-Segovia is supported by grant DER2016-76053-R (MINECO/FEDER, UE).

\section{References}

[1] E. G. Gatev, W. N. Goetzmann, and K. G. Rouwenhorst, "Pairs trading: performance of a relative average arbitrage rule," Review of Financial Studies, vol. 19, 1999.

[2] B. Do and R. Faff, "Does simple pairs trading still work?" Financial Analysts Journal, vol. 66, no. 4, pp. 83-95, 2010.

[3] B. Do and R. Faff, "Are pairs trading profits robust to trading costs?" Journal of Financial Research, vol. 35, no. 2, pp. 261-287, 2012.

[4] H. J. Chen, S. Chen, and Z. Chen, F. Li, Empirical investigation of an equity pairs trading strategy," Management Science, vol. 65, no. 1, pp. 370-389, 2017.

[5] G. Vidyamurthy, Pairs Trading: Quantitative Methods and Analysis, John Wiley \& Sons, Hoboken, NJ, USA, 2004.

[6] Y.-X. Lin, M. McCrae, and C. Gulati, "Loss protection in pairs trading through minimum profit bounds: a cointegration approach," Journal of Applied Mathematics and Decision Sciences, vol. 2006, pp. 1-14, 2006.

[7] H. Huspaningrum, Y. X. Lin, and C. M. Gulati, "Finding the optimal pre-set boundaries for pairs trading strategy based on cointegration technique," Journal of Statistical Theory and Practice, vol. 4, no. 3, pp. 391-419, 2010.

[8] K. F. Law, W. K. Li, and P. L. H. Yu, "A single-stage approach for cointegration-based pairs trading," Finance Research Letters, vol. 26, pp. 177-184, 2018.

[9] M. Clegg and C. Krauss, "Pairs trading with partial cointegration," Quantitative Finance, vol. 18, no. 1, pp. 121-138, 2018.

[10] C. L. Dunis, R. Ho and R. Ho, Cointegration portfolios of European equities for index tracking and market neutral strategies," Journal of Asset Management, vol. 6, no. 1, pp. 33-52, 2005.

[11] A. Galenko, E. Popova, and I. Popova, "Trading in the presence of cointegration," Journal of Alternative Investments, vol. 15, no. 1, pp. 85-97, 2012.

[12] L. Yiyun and K. F. Law, "Systematic risk in pairs trading and dynamic parameterization," Economics Letters, vol. 202, Article ID 109842, 2021.

[13] R. J. Elliott, J. Van Der Hoek, and W. P. Malcolm, "Pairs trading," Quantitative Finance, vol. 5, no. 3, pp. 271-276, 2005.

[14] B. Do, R. Faff, and K. Hamza, "A new approach to modeling and estimation for pairs trading," in Proceedings of the 2006 Financial Management Association European Conference, pp. 87-99, Capri, Italy, June 2006.

[15] J. W. Jurek and H. Yang, Dynamic Portfolio Selection in Arbitrage. Working Paper, Harvard University, Cambridge, MA, USA, 2007.

[16] W. K. Bertram, "Analytic solutions for optimal statistical arbitrage trading," Physica A: Statistical Mechanics and Its Applications, vol. 389, no. 11, pp. 2234-2243, 2010.

[17] M. Cummins and A. Bucca, "Quantitative spread trading on crude oil and refined products markets," Quantitative Finance, vol. 12, no. 12, pp. 1857-1875, 2012.
[18] M. Bock and R. Mestel, "A regime-switching relative value arbitrage rule," Operations Research Proceedings, vol. 14, 2008.

[19] C. W. S. Chen, M. Chen, and S. Y. Chen, "Pairs TIn: huynh VN," in Modeling Dependence in Econometrics. Advances in Intelligent Systems and Computing, V. Kreinovich and S. Sriboonchitta, Eds., Vol. 251, Springer, Berlin, Germany, 2020.

[20] A. Göncü and E. Akyıldırım, "Statistical arbitrage with pairs trading," International Review of Finance, vol. 16, no. 2, pp. 307-319, 2016.

[21] J. Liu and A. Timmermann, "Optimal convergence trade strategies," Review of Financial Studies, vol. 26, no. 4, pp. 1048-1086, 2013.

[22] N. Huck, "Pairs selection and outranking: an application to the S\&P 100 index," European Journal of Operational Research, vol. 196, no. 2, pp. 819-825, 2009.

[23] N. Huck, "Pairs trading and outranking: the multi-step-ahead forecasting case," European Journal of Operational Research, vol. 207, no. 3, pp. 1702-1716, 2010.

[24] L. Ferreira, "New tools for spread trading. Futures: news, analysis \& strategies for futures," Options \& Derivatives Traders, vol. 37, no. 12, pp. 38-41, 2008.

[25] R. Q. Liew and Y. Wu, "Pairs trading: a copula approach," Journal of Derivatives and Hedge Funds, vol. 19, no. 1, pp. 12-30, 2013.

[26] Y. Stander, D. Marais, and I. Botha, "Trading strategies with copulas," Journal of Economic and Financial Studies, vol. 6, no. 1, pp. 83-108, 2013.

[27] W. Xie and Y. Wu, "Copula-based pairs trading strategy," Asian Finance Association (AsFA), 2013.

[28] C. Krauss and J. Stubinger, Nonlinear Dependence Modeling with Bivariate Copulas: Statistical Arbitrage Pairs Trading on the S\&P100, IWQWDiscussion Paper Series, University of Erlangen-Nurnberg, Nurnberg, Germany, 2015.

[29] H. Rad, R. K. Y. Low, and R. W. Faff, The Profitability of Pairs Trading Strategies: Distance, Cointegration, and Copula methods. Working Paper, University of Queensland, Brisbane, Australia, 2015.

[30] J. P. Ramos-Requena, J. E. Trinidad-Segovia, and M. A. Sánchez-Granero, "Introducing Hurst exponent in pair trading," Physica A: Statistical Mechanics and Its Applications, vol. 488, pp. 39-45, 2017.

[31] J. P. Ramos-Requena and J. E. Trinidad-Segovia, M. A. Sánchez Granero and M. Á. Sánchez-Granero, An alternative approach to measure co-movement between two time series," Mathematics, vol. 8, no. 2, p. 261, 2020.

[32] M. López-García, M. Sánchez-Granero, J. Trinidad-Segovia, A. Puertas, and F. Nieves, "A new look on financial markets Co-movement through cooperative dynamics in many-body physics," Entropy, vol. 22, no. 9, p. 954, 2020.

[33] M. N. López-García, M. A. Sánchez-Granero, J. E. TrinidadSegovia, A. M. Puertas, and F. J. De las Nieves, "Volatility Comovement in stock markets," Mathematics, vol. 9, no. 6, p. $598,2021$.

[34] H. E. Hurst, "Long-term storage capacity of reservoirs," Transactions of the American Society of Civil Engineers, vol. 116, no. 1, pp. 770-799, 1951.

[35] M. D. 1. N. López García and J. P. Ramos Requena, “Different methodologies and uses of the Hurst exponent in econophysics," Estudios de Economía Aplicada, vol. 37, no. 2, pp. 96-108, 2019.

[36] B. B. Mandelbrot and J. R. Wallis, "Robustness of the rescaled range $\mathrm{R} / \mathrm{S}$ in the measurement of noncyclic long run statistical 
dependence," Water Resources Research, vol. 5, no. 5, pp. 967-988, 1969.

[37] C.-K. Peng, S. V. Buldyrev, S. Havlin, M. Simons, H. E. Stanley, and A. L. Goldberger, "Mosaic organization of DNA nucleotides," Physical Review A, vol. 49, no. 2, pp. 1685-1689, 1994.

[38] A. W. Lo, "Long-term memory in stock market prices," Econometrica, vol. 59, no. 5, pp. 1279-1313, 1991.

[39] M. A. Sánchez Granero, J. E. Trinidad Segovia, and J. García Pérez, "Some comments on Hurst exponent and the long memory processes on capital markets," Physica A: Statistical Mechanics and Its Applications, vol. 387, no. 22, pp. 55435551, 2008.

[40] R. Weron, "Estimating long-range dependence finite sample properties and confidence intervals," Physica A: Statistical Mechanics and Its Applications, vol. 312, no. 1-2, pp. 285-299, 2002.

[41] W. Willinger, M. S. Taqqu, and V. Teverovsky, "Stock market prices and long-range dependence," Finance and Stochastics, vol. 3, no. 1, pp. 1-13, 1999.

[42] A.-L. Barabási and T. Vicsek, "Multifractality of self-affine fractals," Physical Review A, vol. 44, no. 4, pp. 2730-2733, 1991.

[43] T. D. Matteo, T. Aste, and M. M. Dacorogna, "Long-term memories of developed and emerging markets: using the scaling analysis to characterize their stage of development," Journal of Banking \& Finance, vol. 29, no. 4, pp. 827-851, 2005.

[44] J. Barunik and L. Kristoufek, "On Hurst exponent estimation under heavy-tailed distributions," Physica A: Statistical Mechanics and Its Applications, vol. 389, no. 18, pp. 3844-3855, 2010.

[45] J. P. Ramos-Requena, J. E. Trinidad-Segovia, and M. Á. Sánchez-Granero, "Some notes on the formation of a pair in pairs trading," Mathematics, vol. 8, no. 3, p. 348, 2020.

[46] A. Fernández-Pérez, M. N. López-García, and J. P. RamosRequena, "On the sensibility of the Pairs Trading strategy: the case of the FTS stock market index," Studies of Applied Economics, vol. 38, no. 3, 2021.

[47] M. A. Sánchez-Granero and K. A. Balladares, J. P. RamosRequena, J. P. Ramos-Requena, and J. E. Trinidad-Segovia, Testing the efficient market hypothesis in Latin American stock markets," Physica A: Statistical Mechanics and Its Applications, vol. 540, Article ID 123082, 2020.

[48] K. Balladares, J. P. Ramos-Requena, J. E. Trinidad-Segovia, and M. A. Sánchez-Granero, "Statistical arbitrage in emerging markets: a global test of efficiency," Mathematics, vol. 9, no. 2, p. 179, 2021. 